\title{
Rüya İçinde Rüya: Elif Hümeyra Aydın'ın "Kesik Süt Tadı” Öyküsüne Psikanalitik Bir Yaklaşım
}

\author{
İsmail TURAN ${ }^{1}$
}

\section{Öz}

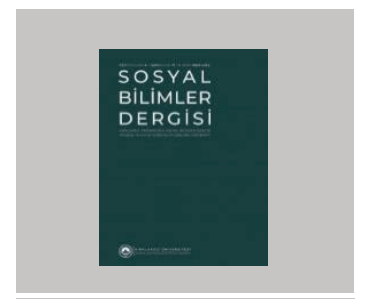

Makale Türü

Araştırma Makalesi

Başvuru Tarihi

30.04.2021

Kabul Tarihi

18.06.2021

$\mathrm{DOI}$

10.47140/kusbder.930191
Psikanaliz, insan zihninin bilinç tarafını inceleyen ve bunlarla ilgili tedavi yöntemleri oluşturan bir bilim dalıdır. Psikanaliz edebiyat kuramında ise yazarın/şairin bilinçdışı ve bilinçaltı yönlerinin eserlerine yansımasını ele alır. Freud, rüyaları yazarın bilinçaltının göstergesi olarak değerlendirmesiyle birlikte edebi eserlerdeki tezahürü üzerine birtakım çıkarımlarda bulunur. Edebi eserlerde bireyler, arayış ile kaçış çizgilerinin tam ortasında kalarak bir çıkmaza girer. Bu çalışmada Elif Hümeyra Aydın'ın Dergâh Yayınlarından çıkan Doğum Lekesi adlı kitabındaki "Kesik Süt Tadı" adlı öyküsünde bu çıkmazın tezahürleri görülür. Bu öyküde yazar, karakterlerin bilinçaltı ve bilinçdışı yönlerine dikkatleri çeker. Yazar, kahramanların iç ve dış çatışmalarına geniş yer verirken annesiyle yaşadığı iletişimsizliği de ön plana çıkarır. Öyküde karakterin genellikle bir kaçış ve arayış içinde olduğu görülür.Bu çalışmadaki amaç, Freud'un geliştirdiği psikanalitik yöntemin altyapısını oluşturan bilinçaltı, bastırma, sanrı, rüya, gündüz düşleri, Elektra Kompleksi gibi kavramlar etrafında yer alan karakterleri, psikanalitik bir okumayla değerlendirmek ve psikanalitik edebiyat kuramı çerçevesinde incelemektir.

Anahtar Sözcükler: psikanalitik, öykü, bilinçaltı, rüya, elektra kompleksi

\footnotetext{
1 Kırklareli Üniversitesi Sosyal Bilimler Enstitüsü Türk Dili ve Edebiyatı Ana Bilim Dalı YL Öğrencisi, turan.ismail.tde@gmail.com, 0000-0003-4622-4301.
} 


\title{
Dream Inside a Dream: To The Story of "Kesik Süt Tadı" by Elif Hümeyra Aydın a Psychoanalytic Approach
}

\author{
İsmail TURAN²
}

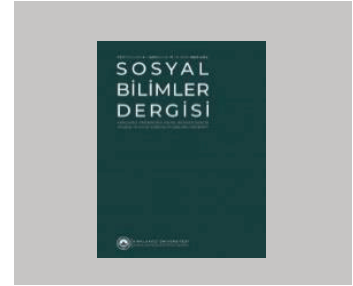

Article Type

Derleme Makale

Application Date

2021-04-30

Acceptance Date

2021-06-18

$\mathrm{DOI}$

10.47140/kusbder.930191

\begin{abstract}
Psychoanalysis is the conscious side of the human mind, science and related sane thing. In psychoanalysis literary theory, on the other hand, it deals with the scope of the content that comes from the unconscious and subconscious content of the author. Freud infers from evaluating expression in literary works, along with treating dreams as a guess of the author's undertraining. In literary works, the entrance, the road and the entrance lines are completely accessible, leaving a dead end. In this study, the performances of this section are seen in the child named "Cuted Milk Taste" in the book Le, published by Elif Hümeyra Aydın' Dergah Publishing. In this story, the author draws attention to the subconscious and unconscious of education. The author's lack of communication with a place where the internal and external conflicts of the heroes can be intertwined with large places also comes to the fore. What is seen in the character in the story is that he is in an escape and being understood. The aim of this study is to investigate the infrastructure of Freud's psychoanalytic method, with a psychoanalytic evaluation and psychoanalytic literature education, which includes concepts such as "consciousness, repression, delusion, dream, daytime, Elektra Complex".
\end{abstract}

Key Words: psychoanalytic, story, subconscious, dream, elektra complex

\footnotetext{
2 Kırklareli Üniversitesi Sosyal Bilimler Enstitüsü Türk Dili ve Edebiyatı Ana Bilim Dalı YL Öğrencisi, turan.ismail.tde@gmail.com, 0000-0003-4622-4301.
} 


\section{Giriş}

"Psikanaliz, bilincin doğrudan ulaşamadığı derin ruhsal katmanlarda geçen psişik olaylar öğretisidir."

(S. Freud)

19. yüzyılın sonunda bireyin bilinçaltındaki çözümlemeleri yapmak amacıyla Freud'un geliştirdiği psikanaliz, ilerleyen süreçte edebi eserler üzerine de uygulanmaya başlanarak bu eserlerin çözümlenmesinde önemli bir yöntem hâline gelir. Psikanalitik edebiyat eleştirisi kuramının, edebi eserlerin yorumlanmasında yeni bir yöntem oluşturduğu ve farklı bakış açılarının uygulanan metne yeni açıımlar kazandırdığı görülür.

Psikanalitik edebiyat kuramı, daha çok eserin bilinçdışını ve satır aralarındakilerini anlamaya yöneliktir. "Ayrıca edebi eserler dünyasındaki şahıs kadrosunun birbirlerine sergiledikleri davranışların derinliklerinde yatan güdü ve reflekslerin tespitinde, davranışların anlamlandırılması yolunda kullanılan göstergelerin şifre çözümünde, karakterlerin rüyalarının yorumlanması, rüya yorumlarının olay örgülerine katkısı gibi daha pek çok bakımdan..." da bu kuram, edebiyatta önemli kapılar aralar (Emre, 2006, s. 68).

Psikanalitik kuramının temelini, birey davranışlarının bilinçli olanlarından ziyade bilinçdışı olanlara dayandığı düşüncesi oluşturur. Psikanalizle bireyin korkuları, endişeleri, arzuları vb. çözülmeye çalışılır. Psikanaliz, dilin şahsi alanı içerisinde kendine yer bulamayan durumların ortaya çıkması konusunda işlevsel bir özelliğe sahiptir. Lacan, bilinçdışını açıklamaktan ziyade bilinçdışını oluşturan unsurların çözümlenmesi gerektiğini düşünür (Lacan, 2013).

İsmet Emre, yazarın eseri oluştururken ki bilincinin önemli olduğunu ve bu bilinci irdelemenin edebiyat psikolojisinin temeline okurları ulaştırdığına dikkat çeker ve psikolojinin yazarın sıradan insandan farklı özellikleri olduğunu, yazara özgü olan duygu karışıklıklarını Wilhelm Reich'in de ifadesiyle "us yarılması" olarak tanımlar:

“Günlük yaşantısını bir tarafa bırakırsak yazar, masanın başına oturup yazmaya başladığı andan itibaren artık bilinçaltı okyanusundan bilinç kıyılarına malzeme taşıyan bir aracı olmakla kalmayıp aynı zamanda görünür dünyaya çoğu insanın ulaşmaya cesaret edemeyeceği bilinç dışı ve bilinç üstü alanlardan da ciddi veriler taşır. Bu yönüyle bakıldığında yazar-öznenin varlığı bizi doğrudan edebiyat psikolojisinin temellerini irdeleme ve oluşturmaya sevk eder" (Emre, 2009, s. 322).

Psikanalizin daha ilk ortaya çıkışından itibaren nevrotik belirtilerin nedenlerini, bunların kalıtımsal psikolojiyle bağlantılı bir çalışmaya ihtiyaç duyduğunu ve bunu gerçekleştirdiğini belirten Freud (2012, s. 81), eseri ve yazarını ön planda tutarak psikanalitik bir analiz yapar, bunu birçok sanat eserine ve eserinin yazarına uygular. Freud, sanatçıyı oyun oynayan bir çocuğa benzetir. Nasıl, bir çocuk hayal kurarak kendi dünyasını oluşturabilirse 
sanatçı da hayal dünyasındakileri belirli bir imgeler etrafında okurda merak uyandıracak bir biçimde sunabilir. Burada çocuğun oyunuyla sanatçının okura sunduğu eserin ortak özelliği hayal kurma edinimidir.

Freud, yazarın yaratma ediniminin içerisinde nevrotikliği barındırdığını söyler. Bu edinim sonucunda oluşan eserin, yazarın bilinçaltındaki arzularının, isteklerinin ve korkularının sembollerini taşıdığını belirtir. Bu da eserlere uygulanış biçimini göstermesi bakımından bize yol gösterici niteliktedir. "Her birey gibi, şair ve yazarların da 'bilinçdışı' bir takım fantezileri vardır. Sanat eseri, sanatçının bilinçaltında bulunan bu fantezilerden doğmuştur" (Budak, 2009, s. 14). Ali İhsan Kolcu da, "Freud'a göre sanatçı nevrotik bir kişiliktir yani ruh hastası sayılır. Romantikler sanatçıdaki başkalaşımı deha ve dâhilik kavramlarıyla açıklamıştır. (...) Sanatçı bütün insanlar adına konuşan kimsedir. Birtakım nevrotik durumların sahibi insan, içgüdüler, itiler ve dürtüler içinde bir karmaşaya sahiptir" diyerek Freud'un yazarlar/sanatçılar hakkındaki görüşlerini açıklar (Kolcu, 2008, s. 200).

Bu çalışmada Elif Hümeyra Aydın’ın Dergâh Yayınlarından çıkan Doğum Lekesi kitabındaki "Kesik Süt Tadı" adlı öyküsünü; Freud’un geliştirdiği psikanalitik yöntemin altyapısını oluşturan bilinçaltı, bastırma, sanrı, rüya, gündüz düşleri, Elektra Kompleksi gibi kavramlar etrafında yer alan karakterler, psikanalitik bir okumayla değerlendirilir.

\section{Akıldışı Bir Kavram: Rüya}

Türk edebiyatında geçmişten günümüze değişen ve gelişen hikâye anlatma geleneği, günümüzde modernleşen dünyanın yabancılaştırdığı bireyin dışlanmış, itilmiş olmasını ve sıradanlığını duyarlılıkla işlemeye devam eder. Modern yaşamın makineleştirdiği ve tekdüzeleştirdiği bireyin duygularındaki değişimler; onu hissizliğe, iletişimsizliğe sürükler ve bu, bireyin psikolojik yıkımlara uğramasına sebep olur. İçe kapanık biri olarak kendi bireyselliğini kazanamamış olan kahramanlar, bir boşluğun içindedir ve kendilerini değersiz hisseder.

Elif Hümeyra Aydın, öykülerinde bu özelliklere sahip olan karakterleri işler. Aydın’ın öykülerine yapılacak olan psikanalitik okumaların, yapıtın özüne inmemizi sağladığı görülür. Her eserin merkezinde bilinçdışı bir fantezi bulunur ve bu fantezi psikanalizin geliştirdiği metotlarla çözülebilir ve anlam kazanabilir.

Annesi, anneannesi ve kahraman-anlatıcı, tatil için gittikleri yeni köy evlerinin (yazlık ev) yüksek girişine konmuş çekyatta; sağında annesi, annesinin yanında sadece "bumburuşuk" bir yüz olarak gördüğü anneannesi ile otururlar. Öykü de bu üç kadın ile başlar: "Ananem, annem ve ben." Kahraman-anlatıcı, annesinin anneannesine karşı sarf ettiği sözler ve düşüncelerle ona (anneannesine) karşı bir bakış açışı geliştirerek bu 
düşüncesini, “...tüm iyimserliğimle, altı kişilik her yemek masasının yedinci kişisi, sığamadığı masalara düşman" diye ifade eder (Aydın, 2019, s. 10). Annesinin ablasını övmesi, kendisinin sürekli mızmızlanıp durduğunu söylemesi kahramanın annesine karşı olan öfkesini daha da arttırır. Ne kadar öfkeli olsa da annesinin peşinden ayrıl(a)maz. Başkalarıyla paylaşamama durumu gelişir; kahraman-anlatıcı, kendisinin her hâliyle annesinin kopyası olduğunu düşünür. Herkesin annesinin yanından ayrılmasına rağmen bir tek kendisinin yanında kaldığını düşünür. Belki de annesi de anneannesi için aynı şeyi düşünüyordur. Bu süreklilik, kahraman-anlatıcının doğuracağı çocuklarda da geçerli olabilir.

Hiçbir şekilde ve hiçbir zamanda tam olarak annesine karşı doyum noktasına ulaşamayan kahraman-anlatıcı, yaşadığı hayal kırıklıklarını, "dünya, memelerini senden kaçıran bir anneymiş. Tam yakaladığında, işte dediğinde, gelen sütün miktarı, hayal kırıklığı" diye ifade eder. Bebeklik döneminde bile sömürücü bir düşünceyle, yetmezlik korkusuyla hep annesini emer, hep içine çeker, hapsetmek ister. Buna rağmen yine de doymak bilmez. Üstünde doymamışların huzursuzluğu, kursağında kalan "kesilmiş süt tadı”yla annesine karşı hep eksiklik hisseder. Fakat bunun da son bulmayacağının bilincindedir. Bu eksikliği, doymazlığı sona erdiremeyeceğinin farkındadır. Tıpkı annesinin kendi annesine doymamış olması gibi. Öykü sonunda yazar, kahramanları bu çıkmazdan kurtarmak için evin karşı taraflarında bir ses duyurur. Trafo patlar, rüyadan uyanırlar ve gerçeğe, hayata ve çekilmez dünyaya dönerler.

Freud, rüyaları akıldışı bulur. Gizli arzu ve dürtülerimizin ürünü olarak görür. Rüyalar, bireyin içindeki bastırılmış duyguların kıyafet değiştirerek dışarı çıkmasıdır. Şimdiki zamana değil, çocukluk zamanına ait istek ve fantezileri ifade eder. Çatışma hâlindeki dürtülerin etkisiyle ortaya çıkar. Aşırı enerjiye sahip olan bu dürtülerin boşalmak için çabası sırasında bir çeşit savunmayla karşılaması muhtemeldir. Freud, "her düşün bir istek doyurmayı temsil ettiği biçimindeki görüşü düş kuramının temeli” (Tükel, 2000, s. 15) olarak görür ve bunu "düş bir gizin açığa vurulması, ama eksik terimlerle açığa vurulması" diyerek de ifade eder (Freud, 1994, s. 8). "Rüyanın nedensizmiş gibi görünen akışı, ansızın değişen sahneleri, çatışan duyguları, yer ve huy değiştiren insanları aynı karakterin birkaç kişiliğe bölünmüş hâlleri, bastırılan geri dönmüş biçimi, arzunun kılık değiştiren bitmez tükenmez oyunları, kâbusun esenliğe, esenliğin kâbusa dönüşen bozulumları..." eserlere aktarmak için rüyanın işlevselliği büyük bir öneme sahiptir (Temizyürek, 2010, s. 568). Nitekim Freud’un rüyalara ilişkin üç temel kaynağını Oğuz Cebeci, “...bunlardan ilki, yakın zamanda yaşadığımız ve rüyanın içeriği ile ilgisi olmayan ve kısaca 'günün kalıntısı' (day resiude) adı verilen bazı olay ve durumlara ilişkin malzemeden oluşur. Ikinci unsur, kişinin çocukluk döneminden getirdiği ve 'zaman ve yer' kavramlarına sahip olmayan bilinçaltında tuttuğu malzemedir. Üçüncü kaynaksa bedene ilişkin unsurlardır; örneğin 
susayan birinin rüyasında su içtiğini görmesi durumunun örneklediği gibi, fizyolojik gereksinimlerin rüya içeriği üzerindeki etkisini gösterir" şeklinde açıklar (Cebeci, 2004, s. 293-294).

Rüyalar üzerine Freud'un cinsellik algısından daha farklı yaklaşan Jung, rüyaların cinsel olmasının ötesinde mesajlar taşıyabileceği ve bu mesajların çok önemli olabileceğini düşünür. Jung, rüya gören bireyin geçmişinden çok bugününe ışık tuttuğuna ve mevcut olan an hakkında bilgi verdiğine inanır. Eagleton (2004, s. 195) ise, "...bilinçdışına giden 'anayol' rüyalardır. Rüyalar bize bilinçdışımızın işleyişine göz atma ayrıcalığını sağlarlar. Freud için rüyalar, temelinde bilinçdışı isteklerin simgesel tatminleridir: rüyalar simgesel bir biçime bürünmüşlerdir, çünkü eğer bu malzeme dolaysız bir biçimde dışa vurabilseydi, bizi uyandıracak kadar rahatsız ve şoke edici olabilirdi. Biraz uyuyabilmemiz için bilinçdışı yardımsever bir tavırla kendi anlamlarını gizler, çarpıtır ve yumuşatır, böylece rüyalar, şifrelerinin çözülmesi gereken simgesel metinlere dönüş[tüğünü]" söyler.

Aslında öykünün geneline bakıldığında, "hikâyenin kurgusunu oluşturan öznenin direnişinin sonunda yaşadığı düş kırıklıkları (...) aslında modern çağda çoğu insanın yaşadığı bir durum" olarak görülebilir (Yeter, 2018, s. 221). Yazar, annesinin anneannesini kızına karşı hep kötülemesiyle aslında kızın annesi hakkındaki görüşlerini daha ilk sayfadan okura hissettirir. Çekyatta bir gözü annesinde bir gözü anneannesinde olan kahramananlatıcı, ironik bir anlatımla okurlarını eserin içinde tutmayı başarır. Ablasının ta çocukluktan itibaren annesi tarafında kayırılmasını sindiremez. Bunu dile getirmek için müsait zaman arar. Bunu dile getirirken de içindeki öfkeyi hissettirmek için fantastik ögeleri kullanır.

“Öfkem köpürdükçe bir dağ devirdim. Tuttum elimi bir nehrin yatağına set yaptım, iki köyü su bastı, insanlar böcekler kaçıştılar. Tek üflememle orta Anadolu şehrinin ekinlerini talan ettim. Coğrafya öfke kaldırıyordu" (Aydın, 2019, s. 11).

Yazar, kullandığı fantastik anlatımla “...böylesine zengin bir malzeme sunarak kendi duygularını kısmen [de olsa] tatmin etmeyi" amaçlar (Yeter, 2018, s. 221). Yazlık eve giderken dahi annesine karşı bir öfke içinde olan kahraman-anlatıcı, gördüğü bir rüyanın üzerindeki etkisini annesine anlatmak, içindekileri boşaltmak ve bir nevi kusmak ister. Köye geldiğinde yaşadığı bu çıkmazdan kurtulmak için onlarca uğraş arar, bulur fakat yine de işin içinden çıkamaz.

Kahvaltıda yaşanan uzun bir sessizlik sonrasında annesi, sıradan şeyler üzerine konu açar ve o, annesiyle onlar üzerine konuşmaya başlar. Günler böyle sıradanlıklarla geçer. Anne yine bir sessizlik sonrasında kahramanın çocukluğundan konu açar. Sonra rüyalardan bahsederler. Kahraman-anlatıcı, daha çok rüyalarda yaşadıklarının bilincine varır. Öykü 
içinde bu üç kadın; aslında aynı davranışlara, geçmişe ve özelliklere sahiptir. Her şeyiyle, her varlığıyla tek bir kadın... Kuşaktan kuşağa geçen bir özellikler bütünü...

Bir yazarı yazmaya iten etkenin eğer onun bastırılmış dürtülerinden kaynaklanmaktaysa bu dürtüler, önünde sonunda yazarın ortaya koyacağı edebi metinlerde kendisine yer bulur (Moran, 2000, s. 152). Aydın’ın kurgularında olağanüstü atmosferin oluşmasında önemli bir yere sahip olan rüyalar, arzuların gerçekleşmesine yöneliktir. "Anne çocuk ilişkisinin özne toplum ilişkisinin önüne geçmesi, çocuğun bilinçdışının annenin bilinçdışı doğrultusunda biçimlenmesi riskini ortaya çıkaracaktır" (İzmir, 2013, s. 293). "Kesik Süt Tadı" öyküsünde kahraman-anlatıcı, annesiyle özdeşleşerek onun yerini almaya çalışır. Böylelikle anne ile kız arasında rekabet oluşur (Freud, 1996, s. 141).

Anneanne, anne ve kızın yaşadığı çatışmanın anlatıldığı bu öyküde yazar, kızın annesiyle birbirlerine rüyalarını anlattıklarını, rüyaların üzerine yorumlar yaptıklarını ifade eder. Fakat kahraman-anlatıcının annesine anlat(a)madığı bir rüyası vardır. Bu rüyayı şu şekilde açıklar:

"Yaşamımın gizlerinden birini açığa vuruyor [bu rüya], beni çıplak bırakıyordu. Oysa ben, anneme karşı bile çıplak kalmak istemiyordum. Psikanalitik yorumlarda veya rüya tabir kitaplarında aynıydı anlamı. İyiye yorulamazdı."

"Gerçeklerden vazgeçtik rüyalarımızı anlattık birbirimize. Karanlık, aydınlık, kanlı, karlı ve artık geleceği mi yoksa sadece geçmişi mi gösterdiğine emin olamadığım rüyalar. O zaman fark ettim ki daha çok rüyalarımızda yaşıyorduk biz. Peki, bu gerçek dünyadan daha büyük rüya dünyası nasıl aktarıldı kuşaktan kuşağa?" (Aydın, 2019, s. 11-12).

"Okuyucunun anlatı labirentleri içerisine davet edildiği bu [öyküde], bir [kadının bebeklik ve gençlik döneminde yaşadığı bu çıkmazları ve bohem ruh hâli] önemli”dir (Yeter, 2018, s. 226). Yazarın okura hissettirmek istediği tam olarak budur. Unutmak istediği bu rüyayı sürekli hatırlayan kahraman-anlatıcı, sonunda annesine anlatır, "belki de anne[sini] biraz rahatsı etmek (...) belki ortamı germek" ister.

"Sık sık görüyorum bu rüyayı. Anne, ben senmişim, yani vücut olarak sen ama düşünce olarak ben. Iş̧te kucağında ya da benim kucağımda bebek var, o da benim bebekliğimin aynı. Fotoğraflarımdaki gibi acayip şişko, semirmiş bir bebek. Emziriyorum. Bebek doymak bilmiyor. O kadar şiddetli çekiyor ki göğsümün ağrıdığını hissediyorum. Hatta sabah kalktığımda da ağrıyordu. O çektikçe memem morarıyor sonra küçülmeye başlıyor, küçülüyor, küçülüyor tabii memeler seninkiler olduğu için küçül küçül itmiyor. Ama sonunda bitiyor, bit kadar kalıyor. Bebeğe bir bakıyorum, ölü cenine düşmüş, kanlı, buruşuk" (Aydın, 2019, s. 14).

Kendisini güvence altına alma eğiliminden dolayı bu karmaşayı çözemeyen kahramananlatıcı, rüyayla baş edemeyince ve bunun etkisini üzerinden atamayıp, bunalımlı duyuşların akınına uğrayınca, annesinin karşısına geçip rüyayı anlatır. 


\section{Anne-Kız Çatışması ve Elektra Kompleksi}

Annenin çocuğun gelişimindeki ve kendisine güven duymasındaki rolü tartışılmazdır. Toplumsal hatta cinsel kimliğinin oturmasında annenin bebeğinin varlığını kabul etmesi çok önemlidir. Illk sevgi kaynağından yani anne tarafından yeterince sevgi ve şefkat görememiş çocukların kişiliğinin gelişimi sekteye uğrar. Freud'un Elektra Kompleksi'nin durumuna göre, "onu yeterince beslememiş olması, onu annesinin başkalarıyla paylaşmaya zorlaması, sevgi beklentilerinin tamamının hiçbir zaman yerine getirememiş olmasıdır" (Freud, 1997, s. 367). Öyküde de kahraman-anlatıcının annesiyle yaşadığı çatışmalarla aslında annesinden kurtulamadığını ve bunun nedenini sorgular.

Eagleton’a (2014, s. 167) göre, “Oedipus sürecinden çıkan insan öznesi bölünmüş, bilinç ile bilinçdışı arasında istikrarsız bir şekilde sıkışmış bir öznedir ve bilinçdışının her zaman yüzeye çıkma tehlikesi vardır." Aslında Odipal dönemde atılan tohumlar, annesinin bazı durumlarından dolayı yetişkinliğine sıçrar. Belli bir yaş aralığında görülen anne nefreti, anne ile kızı arasında bir çatışma oluşturur. Bunlardan dolayı hiçbir zaman anne-kız ilişkisi kurulamaz. Nitekim bakıldığında anne, denizin simgesi olabilecek veyahut onun yerini alabilecek niteliktedir. Anne karnındaki sıvı ile kendisine besin sağlayan, orada kendisini daha güvende hisseden ve ana rahminden çıkmak istemeyen çocuğun davranışları dikkate değerdir. "Kahramanın ana rahminden alınması, (...) hayat karşısındaki güçsüzlüğü [ve kimseler -bizatihi annesi- tarafından fark edilmeyiş̧] hayata tutunmasında bir engeldir" (Yeter, 2018, s. 228). Öyküde de kahramanın ana rahmine dönüş isteği vardır.

"Çocukluğum boyunca yetmiyorsun (...) ilgin, sevgin yetmiyor işte. O zaman daha çok, çok çok, daha; anlıyor musun? Şimdi elimi tutuyorsun, boylu boyunca sarılıyorsun ya; bırakmayacaksın, şu odadan dışarı çıkmayacaksın. Ama sen hep bir elin kapıda durdun. $\mathrm{Ne}$ tamamen gittin, ne rahatça kendini sevdirdin. Karnından çıkmak istemeyişim bundandı. Beni her yere yanında taşımak zorundaydın. Sülük gibi emdim kanını, iliklerine kadar sömürdüm. Tutundum o sıcak karanlığa da fazladan ancak bir ay kalabildim. Beni senden aldıklarında, sen bitmiş haldeydin, bense beş buçuk kiloyla tosun gibi bir bebek. Gözlerimde daha yok mu diyen bir bakış" (Aydın, 2019, s. 17).

$\mathrm{Bu}$ ifadelerden çocuğun güvenli bir ortama ve doyum ihtiyacının karşılanması konusundaki sorunlara verdiği tepkinin ne derece sert olduğu çocuğun yetişkin olduğu zaman anne-babaya verdiği tepkilerden anlaşılır. Oysa birey, annesine karşı hiçbir zaman talep edilen olamaz. Bundan dolayı kendinde yüceltecek hiçbir değer bulamaz ve bu nedenle de çok derin aşağılık kompleksi yaşar. Karen Horney'e göre, çocuğun güven ve doyum ihtiyacı yeterince karşılanmazsa çocukta annesi ve babasına karşı düşmanlık duyguları genişleyebilir (Geçtan, 1995, s. 252-253).

Elektra Kompleksi'nin üç temel ölçütü vardır: Birincisi, babaya duyulan aşırı sevgi; ikincisi, anneye duyulan yoğun nefret; üçüncüsü, kendinden yaşça büyük birine duyulan yoğun 
sevgi. Bu öyküde, Elektra Kompleksi etrafında başlayan anne nefreti, annesinin davranışlarıyla devam eder. Anne ile kız arasındaki paylaşımların azlığı, annenin bir model olarak görülmesine engel olur. Kahraman-anlatıcı, annesini hayatının ve geleceğinin kâbusu olarak görür. "Burada sesime ses verecek olan yalnızca şu kurumuş çayın kurbağaları. Bir cevap bulamam artık yanımdaki düşman ana kızdan” (Aydın, 2019, s. 18). der. Artık sorduğu sorulara cevap alamaz, kendisini güvende hissedecek yakınlığı annesinden göremez.

\section{Gölgesizlik Metaforu ve Aidiyetsizlik}

"Postmodern metinlerde hayata tutunamayan bireyin bir tepkisi olarak düşünebilecek gölgesizlik durumu", bu eserde de okurun karşısına çıkan bir metafordur (Yeter, 2018, s. 229). Kahraman-anlatıcının bir yere ait olamama hissi ve yersiz kalışı, gölgesizlik metaforunu okura hissettirir. Kahraman-anlatıcı, kendisinin nereye ait olduğunu, annesinin nazarındaki durumunu, bir türlü tamamlanamama hâlini ve eksiklik duygusunu öykü boyunca sorgular.

Bireyin bilinçaltındaki anne nefreti, günlük olaylarla sürekli canlı tutulur. Bu nefretin başlangıcı Elektra ile olsa da ilerleyen yıllarda annesinin kendisine olan kayıtsız, bencil ve mücadeleci hâlleri, anne nefretinin hırçın bir karakterde sürekli olmasına ve bu nefretin dışarı vurulmasına neden olur. Annesine benzeme korkusu, bireyin iç dünyasındaki çekişmenin en önemli nedenidir. Anne nefreti, bir yetişkin olarak kadının yaşamında etkilerini devam ettirir. Yaptığı her şeyin artık annesinin birebir aynısı olduğuna değinen kahraman-anlatıcı, bundan dolayı yaşadığı huzursuzluğu ve rahatsızlığı dile getirir.

“...ben niye umutsuz âşık gibi peşine dolanıyorum anne? (...) Ömrüm sana yaltaklanmakla geçti. Şu hâlime baksana, dandik bir kopyan oldum, daha kötüsü gençliğine değil, kırk yaşındaki hâline benziyorum" (Aydın, 2019, s. 16).

Kahraman-anlatıcı, bu çatışmaların aslında sadece kendi annesiyle arasında olmadığına, yüzyıllardır anne-kız ilişkilerinin yaşadığı bir sorun olduğuna, artık son bulması gerektiğine ve bu durumun bir yerde kesilmesinin bir zorunluluk olduğuna değinir. "...ben annemle çekişiyordum, niye beni sevmiyorsun diye. Annem annesiyle. Ananem her gün mezarlıkta kendi annesiyle. (...) Sürüp giden bir şey var aramızda, bunu bir yerde kesmeli mutlaka, (...) bir yerde durdurmalı bunu. (...) Yok, kesilmesi gereken bir yerde kesilip atılır" (Aydın, 2019, s. 16-17).

Ne yazık ki bu devinimin de son bulmayacağına dair inancının az olduğu görülür.

\section{Sonuç}

Her zaman bireyin ruhu sığınacak bir liman arar. Bu, bazen kaçıştır bazen de sığınak. Normal bir süreçte her kız çocuğunda görülen bu ruhsal süreç; annenin bireyle olan çekişmesi, bireyin farklı bir seyir izlemesine sebep olur. Bireyin bu davranışlarındaki her 
görünür nedenin Freud'un "buzdağı" benzetmesinde olduğu gibi bir de "su altında kalan görünmez nedenleri" vardır. Nitekim bireyin annesiyle girdiği rekabetin kökleri çocukluğuna kadar götürülebilir. Bu durum anneyle kız arasında hiç bitmeyen fakat bazen azalıp bazen artan bir gerilimin sürüp gitmesine zemin hazırlar. Bu değerlendirme; Elektra Kompleksi ve rüya izlekleri ışığında bireyin psikolojik derinliklerini ortaya çıkarır, öyküye nüfuz eder, öykü içinde etkili olur ve bir mühendis titizliğiyle inşa edildiğini gösterir.

Yazarın bu kitabında kahraman-anlatıcının ne annesiyle ne de annesiz yapabildiğine tanık olunur. Fakat kahraman-anlatıcı şunun bilincindedir: Bu hayat böyle sürüp gidecek, değişen bir şey olmayacak. Zaten postmodernist düşüncede öznenin yok oluşu olarak da ifade edebileceğimiz durumda, bu arayışın olumlu sonuçlandığını görmek zordur.

Son olarak da zaman ve mekânın bulanıklığı, belirsizliği ve çatışması postmodern düşüncenin bir ürünüdür. Postmodernistlere göre, bireyin arzularının ve düşüncelerinin silikleştirildiği modern dünyada, ezilmiş, hırpalanmış, tekdüze bir hayata hapsolmuş kişiler, geçen süre içinde gölgesizleşmeye ve amiyane tabirle yok olmaya başlamıştır. Bundan dolayı da birey, postmodernistler için hep hayalin peşinde koşmakla, gerçekten uzaklaşmakla bu evrende var olacaktır.

\section{Makalenin Araştırma ve Etik Beyanı Bilgileri}

\begin{tabular}{|c|c|}
\hline $\begin{array}{l}\text { Yazar Çıkar } \\
\text { Çatışması Beyanı }\end{array}$ & Çalışmada adı geçen yazar ve yayınla herhangi bir bağım yoktur. \\
\hline $\begin{array}{l}\text { Yazar Katkı Oranı } \\
\text { Beyanı }\end{array}$ & Bu çalışmanın tamamı şahsıma aittir. \\
\hline $\begin{array}{l}\text { Etik Kurul Onay } \\
\text { Belgesi }\end{array}$ & $\begin{array}{l}\text { Yayın incelemesi süresince etikle örtüşmeyen herhangi bir eylemde } \\
\text { bulunmadım. }\end{array}$ \\
\hline
\end{tabular}

\section{Kaynakça}

Aydın, E. H. (2019). Doğum Lekesi. İstanbul: Dergâh Yayınları.

Budak, A. (2009). Psikanalitik Edebiyat Eleştirisi ve Bir Uygulama Denemesi. Dumlupınar Üniversitesi Sosyal Bilimler Dergisi, 25, 13-26.

Cebeci, O. (2004). Psikanalitik Edebiyat Kuramı. İstanbul: İthaki Yayınları.

Eagleton, T. (2014). Edebiyat Kuramı Giriş (T. Birkan, Çev.). İstanbul: Ayrıntı Yayınları.

Emre, İ. (2006). Edebiyat ve Psikoloji, Ankara: Anı Yayıncılık. 
Emre, İ. (2009). Yeni Türk Edebiyatının Psikoloji Kaynakları. Turkish Studies, 4(1-I).

Freud, S. (1994). Psikanaliz Üzerine (A. A. Öneş, Çev.). İstanbul: Say Yayıncılık. (1996). Beş Konferans ve Psikanalize Toplu Bakış (K. Şipal, Çev.). İzmir: Cem Yayınevi. (1997). Kadın Cinselliği, Cinsellik Üzerine (S. Budak, Çev.). Ankara: A Yayınları. (2012). Psikanaliz Üzerine Konferanslar (I. Kırımlı, Çev.). Ankara: Alter Yayınları.

Geçtan, E. (1995). Psikanaliz ve Sonrası. İstanbul: Remzi Yayınevi.

İzmir, M. (2013). Öznenin Diyalektiği, Hegel, Sartre, Lacan. İstanbul: İmge Kitabevi.

Kolcu, A. İ. (2008). Edebiyat Kuramları. Rize: Salkımsöğüt Yayınları.

Lacan, J. (2013). Psikanalizin Dört Temel Kavramı (N. Erdem, Çev.). İstanbul: Metis Yayınları.

Moran, B. (2000). Edebiyat Kuramları ve Eleştiri. İstanbul: İletişim Yayınları.

Temizyürek, M. (2010). Rüyasındaki Yazarın Kâtibi. M. Varlık (Dü) içinde, Efendime Söyleyeyim (Hasan Ali Toptaş Kitabı) (368-376). İstanbul: İletişim Yayınları.

Tükel, R. (2000). Düşlerin Yorumu Üzerine. T. Parman (Dü) içinde, Psikanaliz Yazıları (1122). İstanbul: Bağlam Yayınları.

Yeter, G. B. (2018). “Hasan Ali Toptaş'ın 'Yatak' Adlı Hikâyesinde Arayış Motifinin Psikanalitik Çözümlemesi. H. Argunşah (Dü) içinde, Sessizliğin Gölgesinde (Hasan Ali Toptaş Kitabı) (219-238). İstanbul: Kesit Yayınları. 


\section{Dream Inside a Dream: To The Story of "Kesik Süt Tadı" by Elif Hümeyra Aydın a Psychoanalytic Approach}

\section{Extented Abstract}

Psychoanalysis is a branch of science that examines the conscious side of the human mind and creates treatment methods related to them. In psychoanalysis literary theory, it deals with the reflection of the unconscious and subconscious aspects of the author/poet on his works. Freud makes some inferences on the manifestation of dreams in literary works, together with the evaluation of dreams as an indicator of the author's subconscious. In literary works, individuals come to a dead end by being in the middle of the lines of search and escape. In this study, the manifestations of this predicament are seen in the story of Elif Hümeyra Aydın's "Taste of Cut Milk" in her book Birth Lekesi published by Dergâh Publications. In this story, the author draws attention to the subconscious and unconscious aspects of the characters. While the author gives wide coverage to the internal and external conflicts of the heroes, he also highlights the lack of communication he experienced with his mother. The role of the mother in the child's development and self-confidence is indisputable. It is very important for the mother to accept the existence of her baby in establishing her social and even sexual identity. The development of the personality of children who cannot receive enough love and affection from their first source of love, namely their mother, is interrupted. In the story, it is seen that the character is usually in an escape and search. The aim of this study is to evaluate the characters around concepts such as subconscious, repression, delusions, dreams, daydreams, Electra Complex, which form the basis of the psychoanalytic method developed by Freud, with a psychoanalytic reading and to examine them within the framework of psychoanalytic literary theory. 